Saudi Journal of Oral and Dental Research

Abbreviated Key Title: Saudi J Oral Dent Res

ISSN 2518-1300 (Print) |ISSN 2518-1297 (Online)

Scholars Middle East Publishers, Dubai, United Arab Emirates

Journal homepage: http://scholarsmepub.com/sjodr/

Original Research Article

\title{
An overview of Silver Diamine Fluoride in Pediatric Dentistry
}

\author{
Doaa Makki Alharbi*, Waad Mosaad Almugren
}

Staff Dentist, Prince Mohammed Bin ABdulaziz Hospital Saudi Arabia

DOI: $10.36348 /$ sjodr.2020.v05i01.002

| Received: 14.12.2019 | Accepted: 24.12.2019 | Published: 11.01.2020

*Corresponding author: Doaa Makki Alharbi

\section{Abstract}

In this Review due to expanding availability of SDF we discuss the effectiveness, indications for appliance and its disadvantages. We will focus on SDF usage in pediatric dentistry. Literature searches were conducted in PubMed/MEDLINE, Embase, Cochrane Central Register of Controlled Trials, to identify studies that are related to our topic "Silver Diamine Fluoride in Pediatric Dentistry" that were published up to May 2018. It is mentioned in the literary works that the most efficient, simplest, and least expensive decays preventive representatives are silver nitrate (which eliminates the causative bacteria) and fluoride (which makes the teeth much less soluble to bacterial acids)). The creation of a silver nitrate fluoride construct -silver diamine fluoride (SDF) -combines these two preventative representatives. SDF is thought to arrest and protect against decay progression by (1) killing the original bacteria, (2) depositing a layer of safety silver phosphate that resists additional decay, and (3) transforming the even more acid soluble hydroxyapatite to the much less soluble fluorapatite.

Keywords: Pediatric dentistry, Silver Diamine Fluoride, silver nitrate fluoride, hydroxyapatite.

Copyright @ 2020: This is an open-access article distributed under the terms of the Creative Commons Attribution license which permits unrestricted use, distribution, and reproduction in any medium for non-commercial use (NonCommercial, or CC-BY-NC) provided the original author and source are credited.

\section{INTRODUCTION}

Tooth decays is the globe's most widespread disease [1].Scoping reviews indicate that affordable preventative agents, that can be applied by family members or community health workers are available, however underused [2].Decay affects far more than a person's oral wellness. The variety of associated issues with neglected caries and toothaches vary from decreased lifestyle to low institution efficiency [3],[4].Poor oral health is likewise associated with prevented growth and development, psychosocial susceptability, reduced well-being and self-efficacy, and reduced locus of control [5]. Several countries such as Japan, China, New Zealand, Australia, and most South American countries have been utilizing silver diamine fluoride for lots of decades for arresting decays. Silver diamine fluoride is offered and accepted for use in numerous Asian and South American nations [2].Lately in 2014 the US Food and Drug Administration (FDA) validated the usage of SDF as a treatment of dentinal hypersensitivity in patients aged 21 and older, yet lots of people have been utilizing SDF off-label for the therapy of cavitated sores, specifically in kids. Several randomised controlled trials are showing that SDF could be used to stop the progression of decays [6], [7].
It is mentioned in the literary works that one of the most reliable, most basic, and least expensive caries preventive agents are silver nitrate (which kills the causative bacterias) and fluoride (which renders the teeth less soluble to microbial acids) [2]. The creation of a silver nitrate fluoride construct - silver diamine fluoride (SDF) - combines these 2 preventive agents [6].Very early studies in healthcare found that silver nitrate is a reliable antimicrobial representative [8]. This led to making use of silver nitrate, silver foil, and silver sutures for the prevention of ocular and surgical infections [9]. These findings led to the application of silver nitrate to treat cavities, creating sclerotic or calcified dentin buildup [10]. The hypothesized device was a potent germicidal impact incorporated with the deposition of silver phosphate salt [11]. Dental professionals labelled silver nitrate 'Howe's solution' after Percy Howe that first methodically reported on its use for cavities prevention.

In this Review due to expanding availability of SDF we discuss the effectiveness, indications for appliance and its disadvantages. We will focus on SDF usage in pediatric dentistry. 


\section{METHODOLOGY}

Literature searches were conducted in PubMed/MEDLINE, Embase, Cochrane Central Register of Controlled Trials, to identify studies that are related to our topic "Silver Diamine Fluoride in Pediatric Dentistry" that were published up to May 2018. Search results were restricted to only English published articles with human subjects.

\section{DISCUSSION}

Potential SDF Benefits to Specific Populations and Patient/Parental Acceptance

Tooth decays continues to be the most common chronic condition on the planet, influencing virtually $35 \%$ of youngsters (aged $2-5$ years) and most grownups by the end of adolescence $[12,13]$. Populaces with reduced socioeconomic condition and those with special healthcare needs have disproportionately high condition rates compared with the remainder of the basic populace [14].Managing tooth decays in the pediatric populace, specifically kids under the age of 3 years, frequently requires pharmacological actions management approaches, consisting of sedation and/or general anesthetic. These strategies are costly and bring the potential threat of fatality. For children under the age of 3 , there are concerns regarding neurological growth with extended or repeated general anesthesia [15]. The usage of SDF to avoid or postpone surgical treatment until after the age of 3 years makes it a possibly attractive adjunctive treatment for handling decays in the very young pediatric population. The usage of SDF in the geriatric population has been shown reliable in apprehending root decays [19], [20].Surgical approaches for handling root decays remain a difficulty in this populace, and having a chemotherapeutic alternative that can be provided in a non-clinical setting has extra advantages. Both geriatric and patients with special healthcare demands can take advantage of non-surgical SDF treatment that has few contraindications (eg, silver allergic reaction) and is scientifically less complicated to deliver than restorative treatment [16].

Adult acceptance for the pediatric population varies based upon the patient's age, patient's sex, and whether the sore to be treated remains in a front or back tooth. Parents are much more accepting of SDF therapy and the resulting black sores for posterior teeth compared to anterior teeth, and more approving for boys vs girls. In the study, over $60 \%$ of parents were accepting of SDF therapy and tooth discoloration of posterior teeth, but only $29 \%$ were approving for anterior teeth [17]. The aesthetic effects of SDF therapy make gaining informed consent critical. Revealing parents clinical photographs of cured lesions is recommended (see Figure 1). There are no studies connected to acceptance of SDF treatment in teenagers, adults, or patients with special healthcare requirements.
Physicians and nurses could use SDF based on their state's procedure acts.

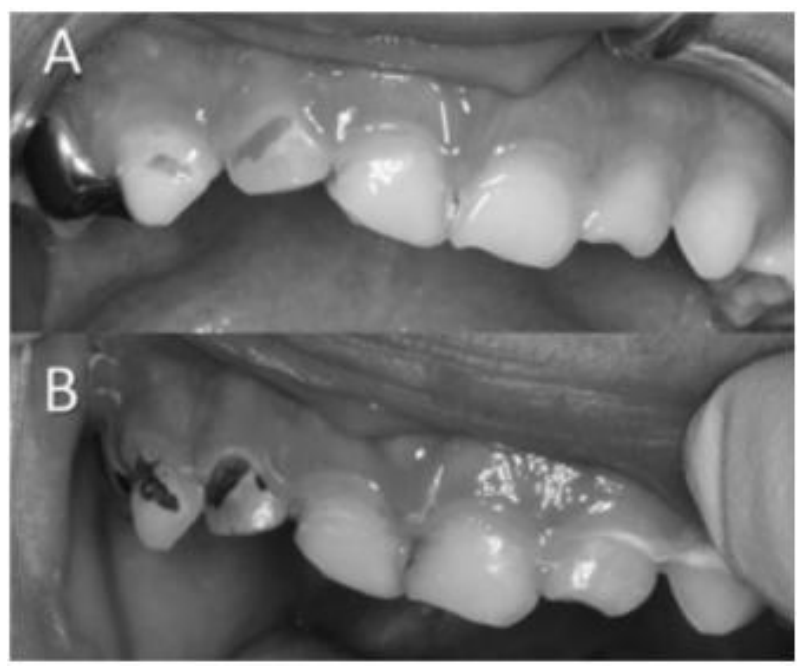

Fig-1: Carious lesions in these primary teeth prior to SDF show a yellow brownish discoloration $(A)$. These same lesions seen one month after SDF treatment show the typically black discoloration (B) and had hardened or re-mineralized based on probing with a dental explorer[18].

\section{Indications for SDF use in residency training}

Many researches have shown efficacy in the pediatric populace, sustaining the opinions cited by program directors [21, 22, 23]. Just recently a record was published highlighting how SDF was used to maintain decays and reduce long-term tooth level of sensitivity in a significantly immunocompromised Chinese teenage [43]. This provides an instance of just how contemporary caries manage representatives could be made use of along with conventional corrective treatment or when conventional treatment is not an option due to the fact that of a patient's medical status. Interestingly, over two times as many respondents differed that SDF should be utilized in long-term teeth versus primary teeth. This could mirror problems relating to usage of strange agents in teeth that will not exfoliate, yet it might also associate to study recommending that SDF is much more effective in primary teeth than long-term teeth. In 2005, Llodra et al. released a contrast of decays apprehension in primary canines and molars versus long-term initial molars. Their searchings for recommend that, when SDF was used two times yearly for 3 years, the preventative portion of new caries in primary teeth was greater [22]. Although the subject of sore place was not particularly resolved in the existing survey, Zhi et al. reported a higher rate of caries apprehension in both primary anterior teeth and buccal/lingual smooth surface areas. They reported that decays lesions in buccal or lingual tooth surface areas had a 15.6 times possibility of ending up being apprehended when compared to occlusal or proximal surface areas which primary anterior teeth were 5.5 times extra most likely to end up being arrested relative to posterior teeth [24]. 
However, the raw apprehension rate in both studies is fairly high.

\section{Silver Diamine Fluoride in dentistry for children}

When kids are very young to have their carious teeth repaired by standard techniques, SDF could be used to reduce or arrest the decays progression. Additionally, SDF application can be a cost-effective means of therapy for many disadvantaged kids or in places where there is a heavy lack of dental personnel. SDF has been in use in many regions (consisting of Australia and China) to arrest tooth decays for several years [25, 26]. In Japan, it has been accepted as a healing agent by the Central Pharmaceutical Council of the Ministry of Health and Welfare for dental therapy for greater than 40 years [27].A solution of 38\% SDF was used in China to apprehend decays [26]. A scientific trial conducted in China reported that SDF was effective in avoiding and apprehending caries in primary anterior teeth of preschool youngsters [29].One more clinical trial in Cuba likewise located that SDF is efficient in decays reduction in primary teeth and first permanent molars in schoolchildren [22]. A clinician in Mexico had actually reported that a 2-year-old kid that had caries in the incisors connected with a nursing bottle had the caries apprehended and hardened after making use of sodium fluoride $(\mathrm{NaF})$ and silver nitrate solution [30]. SDF in various concentrations has been utilized in area dental health projects in Argentina, Brazil and Spain; and additional neighborhood jobs were planned for sub-Saharan Africa and for a number of various other African countries [31]. Although a write-up in an American journal pointed out that there were clinicians in Southern California who used SDF to apprehend caries and to solidify the demineralised dentine of kids with early childhood years decays [32], SDF is not commonly offered in lots of nations in Europe and in the USA. The school dental service in Western Australia used 40\% silver fluoride (AgF) as the standard therapy for deep decays lesions in primary teeth [26]. AgF solution requires a twostage application procedure making use of stannous fluoride $(\mathrm{SnF} 2)$ as a reducing representative. Beneficial outcomes were reported by [33] when utilizing AgF complied with by $\mathrm{SnF} 2$ solution to arrest decays in primary molars in very young children who were difficult to deal with.

Although $\mathrm{AgF}$ is much extra soluble in water $(1820 \mathrm{~g} / \mathrm{L}$ at $15 \mathrm{C})$ compared to the various other silver halides, it creates colourless cubic crystals. SDF consists of ammonia and AgF. The ammonia ions combine with the silver ions to create a complex ion called the diamine-silver ion, $[\mathrm{Ag}(\mathrm{NH} 3) 2]+$. This development of diamine-silver ions is a reversible reaction. The complicated is really steady, and the placement of balance exists within the diamine-silver ions. As numerous silver ions are removed from the solution creating a value less than the solubility product, there is less precipitation of AgF. The SDF is claimed to be much steadier than $\mathrm{AgF}$, and it could be kept in a constant focus for a longer time. In enhancement, SDF is not as alkaline ( $\mathrm{pH} 8$ to 9) as $\mathrm{AgF}$ resolution ( $\mathrm{pH} \mathrm{11).} \mathrm{While} \mathrm{AgF}$ is coming to be much less easily available in dental care, SDF is commonly made use of in $38 \%$ solution as an industrial preparation and is marketed in Japan as Saforide (Toyo Seiyaku Kasei Ltd, Osaka, Japan). Saforide consists of $380 \mathrm{mg}$ water-soluble SDF in $1 \mathrm{ml}$ colourless liquid solution, or about 44,800 ppm of fluoride ions. SDF is likewise commercially made and marketed in South America as Fluoroplat (Laboratorios Naf, Buenos Aires, Argentina) and Safluoride di Walter in $10 \%$ resolution (Polidental, Rio de Janeiro, Brazil). A remedy of $38 \% \mathrm{SDF}$ is likewise readily available in Australia (Creighton Pharmaceutical, Sydney, Australia). There are several benefits of utilizing SDF in caries therapy. Firstly, SDF kills cariogenic bacteria. It precipitates on carious dentine and provides immediate decays apprehension. Its application does not need injection and drilling, and for this reason could be utilized to deal with cavities in worried young kids with extreme dental worry. The patient conformity readies. A number of studies have reported its successful use in young kids [21, 22, 34].Ultimately, SDF has long-proven success; that is, it has been used since the 1960s, especially in Asian nations, without reports of significant or severe complications [21,22]. SDF could be utilized to take on the caries problem in community dental wellness programs in developing countries. The major advantages as mentioned by Bedi and Infirri [31] are as follows.

- Management of discomfort and infection. SDF is effective in arresting decays progression that if left without treatment will trigger discomfort and infection.

- Affordable expense. The expense of SDF treatment is low and need to be affordable in the majority of communities.

- Simplicity of treatment. The procedures are basic. This allows non-dental specialists consisting of primary healthcare employees to be easily educated to use SDF to children.

- Minimal support required. The treatment does not need pricey equipment or assistance infrastructure such as piped water and electrical energy. Consequently, the program is simple and affordable to establish. 
Doaa Makki Alharbi \& Waad Mosaad Almugren; Saudi J Oral Dent Res, Jan 2020; 5(1): 5-10

Table-1: Study list of usage of SDF in pediatrics

\begin{tabular}{|c|c|}
\hline Study (year) & Results \\
\hline $\begin{array}{l}\text { Llodra et al. } \\
\text { [22] }\end{array}$ & $\begin{array}{l}\mathrm{N}=452 \\
\text { Drop-out: } \mathrm{n}=79 \\
\text { SDF was more effective for caries reduction in primary teeth }(80 \%) \text { and first molars }(65 \%) \text { than a control group. }\end{array}$ \\
\hline $\begin{array}{l}\text { Braga et al. } \\
\text { [28] }\end{array}$ & $\begin{array}{l}\mathrm{N}=66 \text { first molars }(22 \text { children) } \\
\text { Drop-out: } \mathrm{n}=8 \text { (molars) } \\
\text { After } 3 \text { and } 6 \text { months, } 10 \% \text { SDF showed a significantly higher capacity than CTT and GIC for arresting caries. A } \\
\text { general reduction in active lesions was noted in all groups }(P<0.05) \text {. }\end{array}$ \\
\hline Yee et al. [35] & $\begin{array}{l}\mathrm{N}=976 \\
\text { Drop-out: } \mathrm{n}=342 \\
\text { The number of arrested carious surfaces was significantly higher in } 38 \% \text { SDF and } 38 \% \text { SDF plus tea groups at } 6 \\
\text { and } 12 \text { months }(P<0.001) \text { and } 24 \text { months }(P<0.01) \text { than it was in } 12 \% \text { SDF and control groups. }\end{array}$ \\
\hline $\begin{array}{l}\text { Dos Santos et } \\
\text { al. [36] }\end{array}$ & $\begin{array}{l}\mathrm{N}=91(345 \text { teeth) } \\
\text { Drop-out: } \mathrm{n}=23 \text { teeth } \\
\text { After } 12 \text { months, SDF was } 1.73(95 \% \mathrm{CI}, 1.38-2.18) \text { times more effective in arresting caries }(\mathrm{RR}, 66.9 \%) \text { than } \\
\text { IRT }(\mathrm{RR}, 38.6 \%)(P<0.05) .\end{array}$ \\
\hline $\begin{array}{l}\text { Monse et al. } \\
\text { [37] }\end{array}$ & $\begin{array}{l}\mathrm{N}=1016 \text { children } \\
\text { Drop-out: } \mathrm{n}=312 \text { children } \\
\text { The caries increment was lower in toothbrushing children than in nontoothbrushing children. HR was } \\
\text { statistically significant for the nontreated children (HR, } 0.43 ; \mathrm{CI}, 0.21-0.87 ; P<0.02 \text { ) and the sealant-treated } \\
\text { children (HR, } 0.15 ; \mathrm{CI}, 0.03-0.072 ; P<0.02) \text {. }\end{array}$ \\
\hline Zhi et al. [24] & $\begin{array}{l}\mathrm{N}=212 \text { (719 lesions) } \\
\text { Drop-out: } \mathrm{n}=31 \\
\text { The group receiving 6-month applications of SDF showed higher caries arrest rates (OR, 2.98; CI, 1.35- } \\
6.69 ; P=0.007) \text { than groups receiving annual applications of SDF or GIC. }\end{array}$ \\
\hline $\begin{array}{l}\text { Duangthip et } \\
\text { al.[38] }\end{array}$ & $\begin{array}{l}\mathrm{N}=304 \text { (1670 lesions) } \\
\text { Drop-out: } \mathrm{n}=29 \\
\text { At } 6 \text { and } 12 \text { months, groups receiving intensive application of SDF had higher caries arrest rates than other } \\
\text { treatment groups (annual SDF and weekly NaF varnish applications). } \\
\text { At } 18 \text { months, the group receiving an annual SDF application presented a higher caries arrest rate }(40 \%) \text { than the } \\
\text { groups receiving intensive SDF and NaF treatments }(P<0.001) \text {. }\end{array}$ \\
\hline
\end{tabular}

Abbreviations: CI, confidence interval; GIC, glass ionomer cement; HR, hazard ratio; IRT, interim restorative technique; NaF, sodium fluoride; OR, odds ratio; RR, relative risk; SDF, silver diamine fluoride.

\section{Disadvantage}

The inherent disadvantage of utilizing SDF to arrest caries is that the lesions will certainly be stained black (figure2). SDF quits cavities progression by forming a hard, black, impermeable layer on the tooth surface area that is immune to decays. It has been recommended that when carious dentine is treated with $\mathrm{SDF}$, silver phosphate (Ag3PO4) is formed and this is weakly soluble [39]. Ag3PO4 is yellow when it is initial developed, but conveniently transforms black under sunshine or under the impact of lowering representatives. Furthermore, the precipitation of silver sulphide additionally adds to the blackening of caries lesions [22]. Some kids and their parents might not be pleased with the aesthetics of this therapy end result. Furthermore, SDF can discolor clothes and the skin of the body. The tarnish triggered by SDF on the skin, although does not cause any type of pain or damage, cannot be quickly gotten rid of and it spends some time for it to go away. SDF solution additionally has a metallic taste that is not too enjoyable. Moreover, gingival and mucosal irritability could occur. For the most parts, the affected tissue turns white and the change is short-term [22]. The white marks (burning) on the gingiva generally heal within 1 to 2 days. Other disadvantages include its level of sensitivity to light, and thus it needs to be maintained in dark/opaque container. Its high fluoride concentration could be poisonous when ingested in big dosages, for this reason precaution needs to be taken especially when it is utilized on really little kids. As SDF stains skin, clothing as well as dental instruments black, it should be managed with care by utilizing protective handwear covers. The cotton pellets taken in SDF needs to be taken care of properly after usage to prevent staining. If there is accidental ingestion of huge quantity of SDF, it is very important to ask for medical help. Throwing up can be induced to avoid its absorption in the body; a $10 \%$ calcium gluconate $(10 \mathrm{ml})$ solution can be carried out. The calcium ions will certainly respond with fluoride ions to form insoluble calcium fluoride $(\mathrm{CaF} 2)$, which cannot be absorbed in the stomach tract. A pointer to handle the staining issue of SDF is to use potassium iodide $(\mathrm{KI})$, which reacts with the free silver ions to create a creamy white compound of silver iodide. An in vitro research has revealed that this SDF/KI application has no substantial difference in protecting against biofilm formation [41] and bacterial inhibition compared with those of SDF alone [40].One more suggestion to stop the black staining is to change the silver ion of $\mathrm{AgF}$ with a silicon ion utilizing ammonium hexafluorosilicate, (NH4)2SiF6, or simply put kind, $\mathrm{SiF}$. An in vitro research reported that $\mathrm{SiF}$ raised acid resistance of bovine enamel and dentine along with SDF [42]. However, the acid resistance of the $\mathrm{SiF}$-treated teeth was inferior to that of the SDF- 
treated teeth. There is no scientific trial on either the $\mathrm{SDF} / \mathrm{KI}$ or $\mathrm{SiF}$ that is released in English. Refresher courses are essential to confirm the appealing outcomes of these in vitro research studies prior to effective use in medical technique.

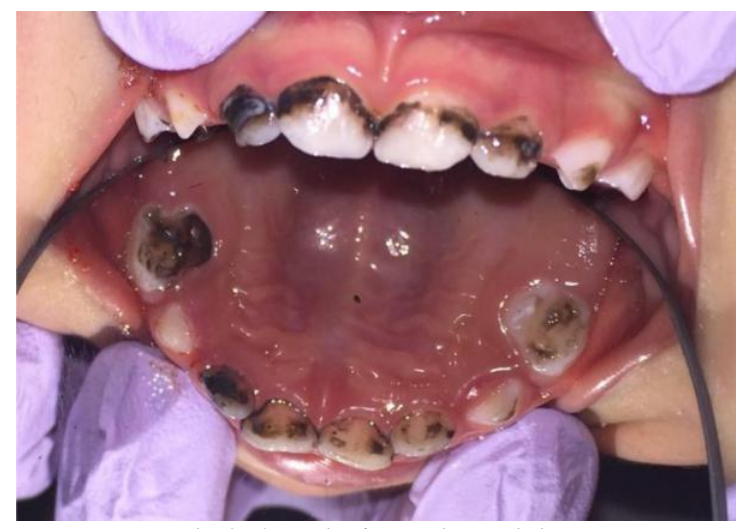

Fig-2: Anterior/posterior staining

\section{CONCLUSION}

It is mentioned in the literary works that the most efficient, simplest, and least expensive decays preventive representatives are silver nitrate (which eliminates the causative bacteria) and fluoride (which makes the teeth much less soluble to bacterial acids)). The creation of a silver nitrate fluoride construct -silver diamine fluoride (SDF) -combines these two preventative representatives. SDF is thought to arrest and protect against decay progression by (1) killing the original bacteria, (2) depositing a layer of safety silver phosphate that resists additional decay, and (3) transforming the even more acid soluble hydroxyapatite to the much less soluble fluorapatite.

"Aside from fluoridated water, silver diamine fluoride may be the single greatest innovation in pediatric dental health in the last century," said Dr. James Nickman, AAPD president and practicing pediatric dentist. "Given its minimal cost and easy, painless application, it could help close the gap in healthcare disparities."

In summary, SDF shows up to be a helpful immediate therapy for children who cannot receive traditional corrective therapy for dental decay. It is efficient for caries arrest and avoidance of new lesions on the teeth where it is applied, and is a minimal intervention treatment that is risk-free and affordable.

\section{REFERENCE}

1. Marcenes, W., Kassebaum, N. J., Bernabé, E., Flaxman, A., Naghavi, M., Lopez, A., \& Murray, C. J. (2013). Global burden of oral conditions in 1990-2010: a systematic analysis. Journal of dental research, 92(7), 592-597.

2. Debas, H. T., Donkor, P., Gawande, A., Jamison, D. T., Kruk, M. E., \& Mock, C. N. (Eds.).
(2015). Disease control priorities, (Volume 1): essential surgery. The World Bank.

3. Blumenshine, S. L., Vann Jr, W. F., Gizlice, Z., \& Lee, J. Y. (2008). Children's school performance: impact of general and oral health. Journal of public health dentistry, 68(2), 82-87.

4. Farber, J. (2004). Oral health and the commonwealth's most vulnerable children: a state of decay. Boston: The Massachusetts Society for the Prevention of Cruelty to Children (MSPCC).

5. Adair, P. M., Burnside, G., \& Pine, C. M. (2013). Analysis of health behaviour change interventions for preventing dental caries delivered in primary schools. Caries research, 47(Suppl. 1), 2-12.

6. Rosenblatt, A., Stamford, T. C. M., \& Niederman, R. (2009). Silver diamine fluoride: a caries "silverfluoride bullet". Journal of dental research, 88(2), 116-125.

7. Gao, S. S., Zhang, S., Mei, M. L., Lo, E. C. M., \& Chu, C. H. (2016). Caries remineralisation and arresting effect in children by professionally applied fluoride treatment-a systematic review. BMC Oral Health, 16(1), 12.

8. Nageli, K. V. (1893). On the oligodynamic phenomenon in living cells. Denkschriften der Schweizerischen Gesellschaft, 33, 174-182.

9. Halstead, W.S. (1985). The operative treatment of hernia. American Journal of the Medical Sciences, 110:13-7.

10. Stebbins, E.A.(1891). What value has argenti nitras as a therapeutic agent in dentistry?. International Dental Journal;12: 661-70.

11. Miller, W.D.(1905). Preventive effect of silver nitrate. Dental Cosmos; 47:901-13.

12. Dye, B.A., Thornton-Evans, G., Li, X., Iafolla, T.J. (2015). Dental caries and sealant prevalence in children and adolescents in the United States, 2011- 2012. NCHS Data Brief, (191):1-8.

13. Dye, B.A., Mitnik, G.L., Iafolla, T.J., Vargas, C.M. [2017]. Trends in dental caries in children and adolescents according to poverty status in the United States from 1999 through 2004 and from 2011 through 2014. J Am Dent Assoc, 148(8):550565.

14. Capurro, D.A., Iafolla, T., Kingman, A. (2015). Chattopadhyay A, Garcia I. Trends in incomerelated inequality in untreated caries among children in the United States: findings from NHANES I, NHANES III, and NHANES 19992004. Community Dent Oral Epidemiol, 43(6):500510.

15. Andropoulos, D.B., Greene, M.F.(2017). Anesthesia and developing brains - implications of the FDA warning. $N$ Engl J Med, 376(10):905907.

16. Chu, C.H., Lee, A.H., Zheng, L., Mei, M.L., Chan, G.C. (2014). Arresting rampant dental caries with silver diamine fluoride in a young teenager suffering from chronic oral graft versus host 
disease post-bone marrow transplantation: a case report. BMC Res Notes, 7:3.

17. Crystal, Y.O., Janal, M.N., Hamilton, D.S., Niederman, R. (2017). Parental perceptions and acceptance of silver diamine fluoride staining. $J$ Am Dent Assoc, 148(7):510-518.

18. Crystal, Y.O., Niederman, R. (2016). Silver diamine fluoride treatment considerations in children's caries management. Pediatr Dent, 38(7):466-471.

19. Hendre, A.D., Taylor, G.W., Chavez, E.M., Hyde, S. (2017). A systematic review of silver diamine fluoride: effectiveness and application in older adults. Gerodontology, 34(4):411-419.

20. Gao, S.S., Zhang, S., Mei, M.L., Lo, E.C., Chu, C.H. (2016). Caries remineralisation and arresting effect in children by professionally applied fluoride treatment - a systematic review. BMC Oral Health, 2016; 16:12.

21. Chu, C.H., Lo, E.C., Lin, H.C.(2002). Effectiveness of silver diamine fluoride and sodium fluoride varnish in arresting dentin caries in Chinese pre-school children. J Dent Res, 81:76770 .

22. Llodra, J.C., Rodriguez, A., Ferrer, B. (2005). Efficacy of silver diamine fluoride for caries reduction in primary teeth and first permanent molars of schoolchildren: 36-month clinical trial. $J$ Dent Res, 84(8):721-4.

23. Fung, M.,Wong, M., Lo, E., Chu, C. (2013). Arresting early childhood caries with silver diamine fluoride: a literature review: Oral Hyg Health, 1:117.

24. Zhi, Q.H., Lo, E.C., Lin, H.C.(2012). Randomized clinical trial on effectiveness of silver diamine fluoride and glass ionomer in arresting dentine caries in preschool children. J Dent, 40:962-7.

25. Gotjamanos, T.(1996). Pulp response in primary teeth with deep residual caries treated with silver fluoride and glass ionomer cement ('atraumatic' technique). Aust Dent J; 41:328-334.

26. Li, Y.J. (1984). Effect of a silver ammonia fluoride solution on the prevention and inhibition of caries. Zhonghua Kou Qiang Ke Za Zhi; 19:97-100.

27. Yamaga, R., Yokomizo, I. (1969). Arrestment of caries of deciduous teeth with diamine silver fluoride. Dent Outlook; 33:1007-1013.

28. Braga, M.M., Mendes, F.M., De Benedetto, M.S., Imparato, J.C.(2009). Effect of silver diammine fluoride on incipient caries lesions in erupting permanent first molars: a pilot study. J Dent Child (Chic), 76(1):28-33.

29. Lo, E.C.M., Chu, C.H., Lin, H.C.(2001). A community-based caries control program for preschool children using topical fluorides: 18- month results. J Dent Res; 80:2071-2074.
30. Aron, V.O. (1995). Porcelain veneers for primary incisors: a case report. Quintessence Int, 26:455457.

31. Bedi, R., Infirri, J.S. (1999). Oral Health Care in Disadvantaged Communities. London: FDI World Dental Press.

32. Duperon, D.F. (1995). Early childhood caries: a continuing dilemma. J Calif Dent Assoc; 23:15-25.

33. Craig, G.G., Powell, K.R., Cooper, M.H.(1981). Caries progression in primary molars: 24-month results from a minimal treatment programme. Community Dent Oral Epidemiol; 9: 260-265.

34. Shimizu, A., Kawagoe, M. (1976). A clinical study of diamine silver fluoride on recurrent caries. $J$ Osaka Univ Dent Sch, 16:103-109.

35. Yee, R., Holmgren, C., Mulder, J., Lama, D., Walker, D., van Palenstein, Helderman, W. (2009). Efficacy of silver diamine fluoride for arresting caries treatment. J Dent Res, 88(7):644-647.

36. Dos Santos, VE, Jr, de Vasconcelos, F.M., Ribeiro, A.G., Rosenblatt, A.(2012). Paradigm shift in the effective treatment of caries in schoolchildren at risk. Int Dent J, 62(1):47-51.

37. Monse, B., Heinrich-Weltzien, R., Mulder, J., Holmgren, C., van Palenstein Helderman, W.H.(2012). Caries preventive efficacy of silver diammine fluoride (SDF) and ART sealants in a school-based daily fluoride toothbrushing program in the Philippines. BMC Oral Health, 12:52.

38. Duangthip, D., Chu, C.H, Lo, E.C. (2016). A randomized clinical trial on arresting dentine caries in preschool children by topical fluorides-18 month results. J Dent, 44:57-63.

39. Yamaga, R., Nishino, M., Yoshida, S., Yokomizo, I. (1972). Diamine silver fluoride and its clinical application. J Osaka Univ Dent Sch, 12:1-20.

40. Knight, G.M. (2006). Inhibition of biofilm formation by silver fluoride and potassium iodide. J Dent Res, 85: Spec Issue B Abst 1268

41. Knight, G.M., McIntyre, J.M., Craig, G.G., Zilm, P.S., Gully, N.J. (2005). An in vitro model to measure the effect of a silver fluoride and potassium iodide treatment on the permeability of demineralized dentine to Streptococcus mutans. Aust Dent J, 50:242-245

42. Kawasaki, A., Suge, T., Ishikawa, K., Ozaki, K., Matsuo, T., Ebisu, S. (2005). Ammonium hexafluorosilicate increased acid resistance of bovine enamel and dentine. J Mater Sci Mater Med, 16:461-466.

43. Chu, C.H., Lee, A.H., Zheng, L., Mei, M.L., Chan, G.C. (2014). Arresting rampant dental caries with silver diamine fluoride in a young teenager suffering from chronic oral graft versus host disease post-bone marrow transplantation: a case report. BMC Res Notes; 7:3. 